Journal of

Cardiology and Vascular Medicine

\title{
Frequency and Distribution of Cardiovascular Disease Risk Factor in Coronary Patients
}

\section{Bindia I. D ${ }^{1}$, Sangare $Z^{2}$, Diop I. B ${ }^{1}$, Regnault $K^{1}$, Mingou J. ${ }^{2, *}$, Dioum $M^{1}$, Sarr E. M ${ }^{1}$, Leye $M^{1}$, Manga $S^{1}$, Dieye $\mathrm{O}^{1}$, Diagne $\mathrm{A}^{1}$, Diene $\mathrm{L}^{1}$}

${ }^{1}$ Department of Cardiology, Fann Hospital University, Dakar, Senegal

${ }^{2}$ Department of Cardiology, Aristide Le Dantec Hospital University, Dakar, Senegal

*Corresponding author: Joseph Mingou, CardiologyDepartment, Aristide Le Dantec Hospital University, Dakar, Senegal, Email: mingoujoseph@gmail.com

Received Date: November 16, 2018; Accepted Date: December 26, 2018; Published Date: December 28, 2018

Citation: Bindia I.D (2018) Frequency and Distribution of Cardiovascular Disease Risk Factor in Coronary Patients. J Cardio Vasc Med 4: 1-5.

\section{Summary}

Introduction: Coronary heart disease, considered as uncommon in sub-Saharan Africa is increasing. This epidemiological situation due to the increase in the prevalence of coronary disease risk factor is induced by a change in lifestyle and new eating behaviours.

Aim: To evaluate the frequency and distribution of cardiovascular disease risk factor in coronary patients hospitalized for coronary angiography.

Method:We conducted a retrospective study from patients' files explored by coronary angiography during the period from April 2013 to January 2016 in the Jacques Bessol Coronary Angiography Center of the Fann University Hospital in Dakar, Senegal.

Results:Two hundred and six patients were enrolled. There were significant differences between men and women participants with male predominance (sex-ratio=3.03). The mean age was $61.7+/-10.7$ years. Most of the patients were less than 70 years old (79.6\% vs. 20.3\%).The frequency of hypertension, dyslipidaemia, diabetes, smoking and obesity was $57.5 \%, 42 \%, 26.6 \%$, $20.8 \%$ and $13 \%$ respectively. Women had a higher frequency of hypertension (70.5\% vs. 53.5\%; $\mathrm{P}=0.002)$, hypercholesterolemia (56.8\% vs. $37.4 \% ; \mathrm{P}=0.001)$, diabetes $(29.4 \%$ vs. $25.8 \% ; \mathrm{P}=0.012)$ and obesity $(27.4 \%$ vs. $8.3 \% ; \mathrm{P}=0.001)$.The frequency of hypertension (55.5\% vs. $66.6 \%$; $\mathrm{P}=0.241)$, diabetes (28.04\% vs. $21.4 \% ; \mathrm{P}=0.245)$ and hypercholesterolemia (43.3\% vs. $38 \%$; $\mathrm{P}=0.642)$ didn't vary significantly according to both gender.Smoking decreased with age ( $25.61 \%$ vs. $2.38 \%$; $\mathrm{P}=0.003)$. More than half of diabetic and nearly two-third of obese patients had at least three cardiovascular disease risk factor.

Conclusion: The most common risk factor in our study, were hypertension, hypercholesterolemia and diabetes. Women cumulated more risk factor than men. Diabetic and obese patients were characterized by the multiplication of risk factor.

Keywords: Cardiovascular disease risk factor, distribution, frequency, coronary heart disease, Dakar (Senegal).

C 2018 The Authors. Published by the JScholar under the terms of the Creative Commons Attribution License http://creativecommons.org/licenses/by/3.0/, which loize.marechal@umontreal.ca

maximilien.laviolette-brassard@umontreal.ca 


\section{Introduction}

Coronary heart disease which is considered to be rare in Africa, has been dangerously increasing in these recent years [1].

Some available statistical data issued from small series showed marked increase in the prevalence of coronary heart disease since CONAFRIC I survey in 1989. This prevalence increases from $3.17 \%$ to $9 \%$ in Ouagadougou in 2012 and 12\% in Dakar in 2008 [2].It seem that this prevalence will double shortly by 2020 with $140 \%$ increase in myocardial infarction mortality $[1,3]$.This epidemiological situation is underlid by an increase in the prevalence of coronary risk factor induced by a change in the lifestyle and new eating behaviours [1]. The synergistic effect of the cardiovascular disease risk factor was emphasizedin the preliminary results of the Framingham epidemiological survey. The fight against the explosion of coronary heart disease will go by the management of cardiovascular disease risk factor [1].

Some epidemiological studieshas been conducted in order to evaluate cardiovascular disease risk factor in industrialized countries, but few have been interested in the situation in Africa, particularly in sub Saharan Africa .

In Senegal, a change in the causes of death in the benefit of cardiovascular disease is occurring due to the change in eating behavior, the tendency to sedentary lifestyle and permanent stress.

\section{Main objective}

To evaluate the frequency and distribution of main cardiovascular disease risk factor in patients hospitalized and explored by coronary angiography in the Jacques Bessol coronarography center ofthe Fann University Hospital in Dakar-Senegal.

\section{Specific objective}

identify cardiovascular disease risk factor in patients

likely to have coronary heart disease;

Determine the prevalence of each cardiovascular disease risk factor

- Study the distribution of these risk factor in populationstudied

\section{Method}

It was a monocentric, retrospective and descriptive study from April 2013 to January 2016 in the Jacques Bessol coronarography center of the Fann University Hospital in Dakar-Senegal.

We included in the study any patients seen or hospitalized in the center who had a coronary angiography The Studied parameters concerned epidemiological, clinics and paraclinical data.Data analysis were performed using the SPSS $^{\circledast}$ Version.10.0. Software.
The Results were expressed as means \pm standard deviation for continuous variables and percentage for discontinuous variables

Confidence intervals were calculated at the risk of $5 \%$.

Chi-2 test was used to analyse the difference between discontinuous variables

A p-value of $<0.05$ was considered significant.

\section{Results}

Two hundred and six patients were enrolled. There were significant differences between men and women participants with a male predominance (sex-ratio=3.03). The mean age of patients was $61.7+/-10.7$ years. Most of the patients were less than 70 years old ( $79.6 \%$ vs. $20.3 \%)$.

The frequency of classical cardiovascular risk factor including hypertension, dyslipidemia, diabetes, current smoking, and obesity was $57.5 \%, 42 \%, 26.6 \%, 20.8 \%$, and $13 \%$ respectively (figure 1 ). Women had a higher frequency of hypertension (70.5\% vs. $53.5 \% ; \mathrm{P}=0.002)$, hypercholesterolemia (56.8\% vs. $37.4 \%$; $\mathrm{P}=0.001)$, diabetes $(29.4 \%$ vs. $25.8 \%$; $\mathrm{P}=0.012)$ and obesity $(27.4 \%$ vs. $8.3 \% ; \mathrm{P}=0.001)$. The frequency of hypertension $(55.5 \%$ vs.66.6\%; $\mathrm{P}=0.241)$, diabetes $(28.04 \%$ vs. $21.4 \%$; $\mathrm{P}=0.245$ ) and hypercholesterolemia ( $43.3 \%$ vs. $38 \%$; $\mathrm{P}=0.642$ ) didn't vary significantly according to both genders. Smoking decreased with age $(25.61 \%$ vs. $2.38 \%$; $\mathrm{P}=0.003)$. More than half of diabetic and nearly two-third of obese patients had at least three cardiovascular disease risk factors. The motif of angiography was dominated by stable angina $(44.5 \%)$ and then myocardial infarction (26.6\%), unstable angina (5.3\%) and without Q waved infarction (5.3\%) (figure 2).

\section{Discussion}

In our study we found a male predominance of 74.9\%. A similar study conducted by Kenyane reported $80.6 \%$ [4]. Our population of study was relatively young, that may partly explain how male were predominant.

The mean age was 61.7 years old, and any etiologies combined were slightly similar to the two African series (57.1 years old) and (63.3 years) [5,4]. A same report was also found in the three EUROASPIRE I, II and III study which showed a mean age of 59,59, 60 years respectively [6].The incidence according to gender and age bracket for all the three MONICA-France registers increase in a very important way in both gender with a greater increasing in women $[7,8]$.

It was underlined in our study a predominance of hypertension, dyslipidaemia, obesity and diabetes among women. In coronary women some risk factor such as diabetes and hypertension are more common [9]. In the other hand, another study showed that women had a higher cardiovascular disease risk factor profile than men, with a higher frequency of diabetes and hypertension of $35.8 \%$ vs. $23.7 \%$ and $68.7 \%$ vs. $54.3 \%$ respectively [10].Abdominal obesity, essentially met after menopause, is frequently associated with diabetes, dyslipidaemia and hypertension, explaining the increase in the prevalence of metabolic syndrome reflecting an accumulation of cardiovascular disease risk factor [11]. 


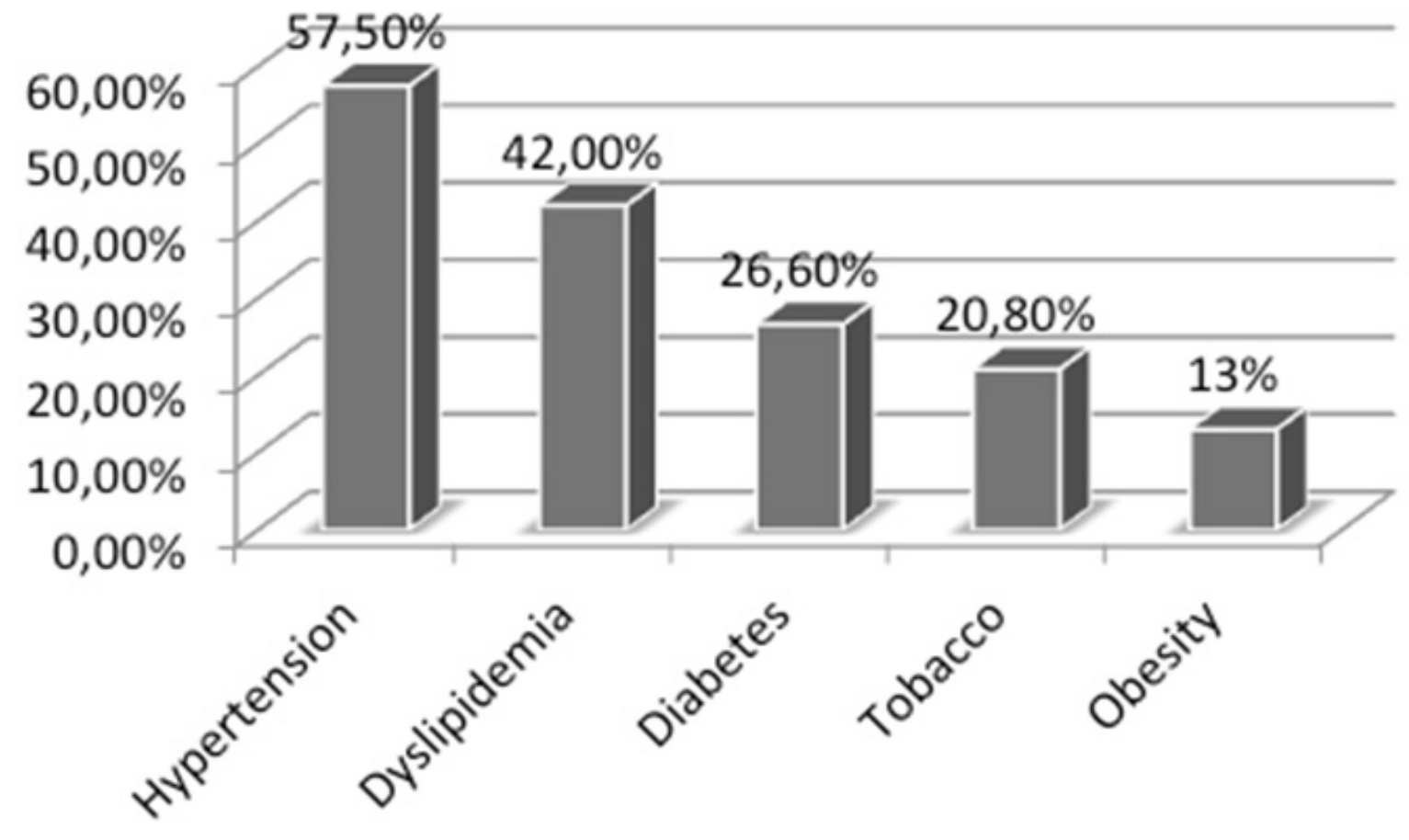

Figure 1: Prevalence of major cardiovascular risk factors

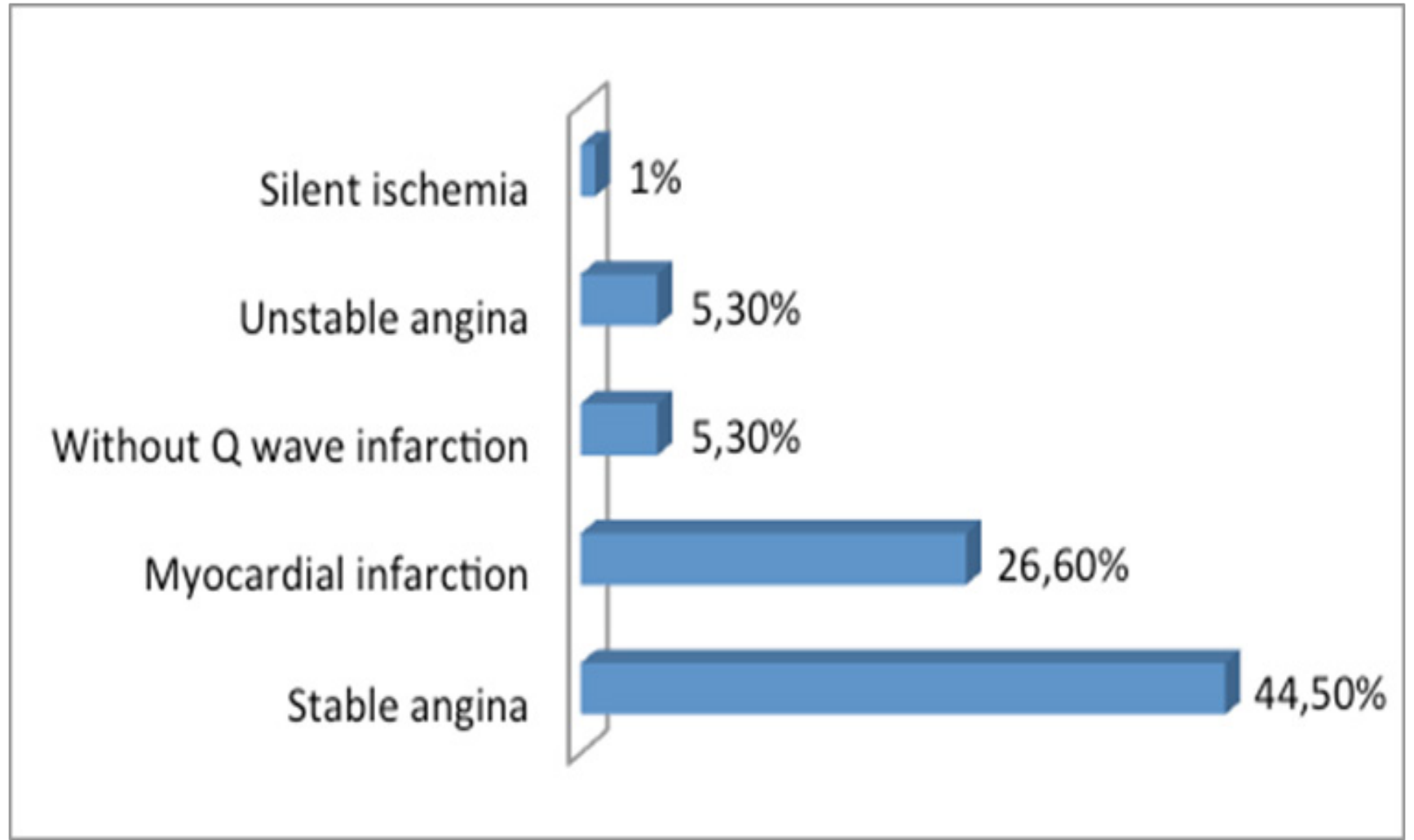

Figure 2: Distribution according to the angiogram 
In our study, only the distribution of the prevalence of dyslipidaemia according to gender seemed to be deviated from the whole data set in certain studies [12]. The analysis of the distribution of risk factor according to age bracket revealed a similarity between the two age group except for smoking poisoning. But it's classically described in many studies that the distribution of risk factor generally vary according to age. Thus, in a French study, it was shown that the frequency of hypertension increased with age whereas dyslipidaemia decreased with advanced age [13].

Another study showed a significant increase in the prevalence of hypertension and diabetes with age in both gender. However, the prevalence of dyslipidaemia increased significantly with age, but only among women [12]. The disparity in our results with those of medical literature can be explained by early exposure of our patients to cardiovascular disease risk factor. The decrease in smoking rate among senior citizen is coherent with the medical literature $[12,13]$.The analysis of the subgroup of diabetic patients in our study showed a frequent association of multiple risk factor including obesity and hypertension. In fact, more than half of diabetic patients ( $53.5 \%$ vs. $7.28 \%$ of non-diabetics $\mathrm{P}=0.0001$ ) had at least three cardiovascular risk factors associated. Similar results were reported in several African studies. Thus, it has been noticed in other studies that in addition to obesity, hypertension was the main risk factor for cardiovascular disease risk associated with diabetes [14]. Moreover, Dembele [15] reported in Mali that the prevalence of hypertension was more frequent in diabetes type2 with a rate of $29 \%$. Even Lokrou [16]in Ivory-Cost and Akintewe [17] in Nigeria reported a prevalence of $31 \%$.

We found that nearly two-third of obese patients (63\% vs. $12.84 \%$ non-obese patients, $P=0.0001$ ) had at least three associated cardiovascular disease risk factors. An African study reported among obese patients, hypertension ( $54,8 \%$ vs. $39,2 \%)$, dyslipidaemia ( $34,5 \%$ vs. $20 \%)$, diabetes $(30,9 \%$ vs. $10,7 \%)$ and smoking $(14,1 \%$ vs. $20,3 \%)$ with significant differences between the two groups [18].

\section{Conclusion}

The most common risk factor in our study were hypertension, hypercholesterolemia, diabetes and a lower rate of smoking patients than in developed countries. Women cumulated more risk factor than men. Diabetics and obese patients were characterized by the multiplicity of risk factor. This reflected the high level of cardiovascular disease risk in most of our patients.

These results have to incite to reconsider imperatively in a hurry the dietary and the lifestyle behaviour in Senegal in order to reduce this morbid situation and the risk of morbidity and mortality from cardiovascular disease.

\section{Reference}

1) GAZIANOTA (2005) Cardiovascular disease in the developing world and its cost-effective management. Circulation 112:3547-3553.

2) Ticolat P, Bertrand Ed, Barabe P et al. (1991) Epidemiological aspects of coronaryarterydisease in African black: about 103 cases. Results of the Multicentresurveycoronafric. Cardio too17:7-20.

3) Okrainec K, Banerjee DK, Eisenberg MJ et al. (2004) Coronaryartery disease in the developing world. Am Heart J148:7-15.

4) Jay S, Gerald Y, Harun O et al. (2012) A prospective review of acute coronary syndromes in an urban hospital in sub-saharanafrica. Cardiovasc j of Afr23:3-18.

5) Mboup MC, Diao M, Dia K, et al. (2014) Acute coronary syndromes in Dakar:clinical, therapeutic and evolutionary Aspects. Pan Afr Med J 19:126.

6) Kotseva K, Wood D, DeBacker G et al. (2009) Cardiovascular prevention guidelines in daily practice: a comparison of EUROASPIRE I, II, III surveys in eight European countries. Lancet373:929-940.

7) Montaye M, Ducimetiere P, Ruidavets JB, et al. (2006)North-South Gradient of coronarymortality and morbidity in France:Recent data from the French registers of ischemicheartdisease, 1997-2002. BEH 8-9:62-64.

8) Ruidavets JB, Hass B, Montaye M, et al.(2006) Lethality of myocardialinfarction of hospitalized patients and itsevolution in the three French registers of ischemicheartdisease, 1997-2002. BEH 8:67-68.

9) Bongard V, Grenier O, Ferrieres J, et al. (2004) Drug prescriptions and referal to cardiac rehabilitation after acute coronary events; comparison between men and women in the French PREVENIR survey. Int J Cardiol 93:217-223.

10) Jacobs AK, Johnston JM, Haviland A, et al. (2002) Improved outcomes for women undergoing comtemporary percutaneous intervention. A report from the National Heart, Lung and Blood Institute Dynamic Registry. J Am Coll Cardiol 39:1608-1614.

11) Wessel TR, Arant CB, Olson MB, et al. (2004)Relationship of physical fitness vs body mass index with coronary artery disease and cardiovascular events in women. JAMA 292: 1179-1187.

12) Elasmi M, Feki M, Sanhaji H, et al. (2009)Prevalence of conventional cardiovascular risk factors in the Great Tunis population. Revue d'Epidémiologie et de Santé Publique 57 : 87-92. 
13) Marques VP, Cambou JP, Ferrieres J, et al. (2001) Distribution and management of cardiovascularriskfactors in coronarypatients:studyprevent. Arch Mal Coeur 94:673-680.

14) Gning SB, Thiam M, Fall F, et al. (2007) Fourcade Diabetesmellitus in sub-SaharanAfrica;Epidemiological aspects, management difficulties. Med too 67:607-611.

15) Dembélé $m$, Sidibe AT, Traore HA et al. (2000) Association blood hypertension and diabetesmellitus in services of internalmedicine at Point G Hospital in Bamako. Med AFR Black 47:276-280.

16) Lokrou A, Koukougnon M (1997) Diabetes and blood hypertension in Ivory Coast. Rev Fr Endocrinol Clin 38:99-106.

17) Kinteweta A, Adetuyibi A (1986) Obesity and hypertension in diabetics nigerians. Trop Geogr Med, 38:146149.

18) Pessinaba S, Komlavi Y, Machiude P, et al. (2012) Obesity in consultation cardiac in Lomé: prevalence and assoc iatedcardiovascularriskfactors-studyin 1200 patients. Pan Afr Med J 12:99.

Submit your manuscript to a JScholar journal and benefit from:

q Convenient online submission

I Rigorous peer review

- Immediate publication on acceptance

I Open access: articles freely available online

ब High visibility within the field

ब Better discount for your subsequent articles Submit your manuscript at http://www.jscholaronline.org/submit-manuscript.php 